\title{
Prevalence of Knee Osteoarthritis and Its Correlation in Women of Rural and Urban Parts of Hoshiarpur (Punjab)
}

\author{
${ }^{1}$ Rajvir Kaur, ${ }^{2}$ Vijay Lakshami Sharma, ${ }^{3}$ Amarjeet Singh
}

\begin{abstract}
Osteoarthritis (OA) is a major cause of enormous disability in both the developed and developing world. The worldwide prevalence estimate for symptomatic OA is $9.6 \%$ among men and $18 \%$ among women. The present study was undertaken with the objectives: To estimate the prevalence of Knee Osteoarthritis (KOA) in women of rural and urban Hoshiarpur and to elucidate the correlates of KOA in women of rural and urban Hoshiarpur. The study was conducted in the rural and urban areas of district Hoshiarpur, Punjab (India) between August 2012-May 2013. The sample comprised of urban (200) and rural (200) females. A semi structured interview schedule was used to interview the study subjects. The prevalence was found to be high in urban area $(21.5 \%)$. The prevalence of KOA was found to be increased with age and was also significantly associated with educational level and menopause.
\end{abstract}

Keywords: Knee osteoarthritis, Prevalence, Women.

How to cite this article: Kaur R, Sharma VL, Singh A. Prevalence of Knee Osteoarthritis and Its Correlation in Women of Rural and Urban Parts of Hoshiarpur (Punjab). J Postgrad Med Edu Res 2015;49(1):32-36.

Source of support: Nil

Conflict of interest: None

\section{INTRODUCTION}

Osteoarthritis (OA) is the most common form of arthritis. It is defined as a heterogeneous group of conditions that lead to joint symptoms and signs which are associated with defective integrity of articular cartilage, in addition to related changes in the underlying bone at the joint margins. ${ }^{1} \mathrm{OA}$ is a major cause of enormous disability in both the developed and developing world and is responsible for loss of productivity. ${ }^{2}$ World Health Report (2002) quoted OA as the 4th leading cause of years lived with disability at global level accounting for $3.0 \%$ of total global YLDs in the year 2000. ${ }^{3}$ It is estimated that, as life expectancy increases the ageing population are expected

\footnotetext{
${ }^{1} \mathrm{PhD}$ Research Scholar, ${ }^{2,3}$ Professor

${ }^{1,2}$ Centre for Public Health, University Institute for Emerging Areas in Science \& Technology, Panjab University, Chandigarh, India

${ }^{3}$ Department of Community Medicine, Postgraduate Institute of Medical Education and Research, Chandigarh, India
}

Corresponding Author: Rajvir Kaur, PhD Research Scholar Centre for Public Health, University Institute for Emerging Areas in Science and Technology, Panjab University, Chandigarh, India Phone: 7589491235, e-mail: rajveersaini7@gmail.com to make osteoarthritis the fourth leading cause of disability by the year $2020{ }^{4}$

Based on prevalence data from the National Centers for Health Statistics, an estimated 15.8 million adults, or $12 \%$ of those between 25 and 74 years of age, have signs and symptoms of OA. ${ }^{5}$ Consultations for osteoarthritis account for $15 \%$ of all musculoskeletal consultations in those aged 45 years old and over, peaking at $25 \%$ in those aged 75 years old and above.

The worldwide prevalence estimate for symptomatic $\mathrm{OA}$ is $9.6 \%$ among men and $18 \%$ among women. ${ }^{6}$ Osteoarthritis ranks fourth among medical problems in women. ${ }^{7,8}$ Therefore, women are at greater risk of knee osteoarthritis than men. Almost every age group is affected by osteoarthritis, but prevalence increases dramatically after age 50 years in men and 40 years in women., ${ }^{9,10}$ Osteoarthritis is ranked as one of the leading causes of disability among elders. ${ }^{2,11,12}$ Despite a lot of available epidemiologic studies on their focus, the exact prevalence of $\mathrm{OA}$ is unknown, owing to the uncertainties and variations of diagnostic definition and reporting mechanisms. The burden of OA can be estimated using data on clinical OA (from physical history and exams), radiographic OA (using X-ray), or symptomatic OA (symptoms plus radiographic evidence). Symptomatic OA, is most relevant for public health purposes as the symptoms like pain, aching, stiffness and swelling bother the affected individuals. ${ }^{13}$

Knee osteoarthritis is the most common form of osteoarthritis. ${ }^{14-17}$ Other presenting signs and symptoms include stiffness that generally improves after 30 minutes of activity, crepitus, swelling and limp. In advanced cases, patients may present with instability symptoms or valgum (knock knee) or varum (bow-leg).

There is currently no cure for OA. Treatment is aimed primarily at symptom relief, improving joint mobility and function, and optimizing consumer quality of life. ${ }^{18}$

Patients consult the specialist doctors when the situation becomes worse. Once the problem starts, the knee osteoarthritis (KOA) remain there with patients for lifetime. None of the available treatment regimes is $100 \%$ effective. All patients are not benefitted by the consultation. In view of the chronic unbearable nature of symptoms, they keep trying different treatment agencies and regimes. They keep on using drugs available over the counter.

Its high prevalence and its moderate-to-severe impact on daily life pose a significant public health problem. ${ }^{19}$ 
Osteoarthritis of the knee is a significant contributor to disability and loss of independence. Despite the high prevalence of osteoarthritis, a disabling disease with limited treatment options, there is a paucity of regional studies in women. The present study was undertaken with the following objectives:

- To estimate the prevalence of KOA in women of rural and urban Hoshiarpur.

- To elucidate the correlates of KOA in women of rural and urban Hoshiarpur.

\section{METHODOLOGY}

The study was conducted in the rural and urban areas of district Hoshiarpur, Punjab (India), between August 2012 and May 2013. Sample size of 400 female residents of rural and urban Hoshiarpur aged 18 and above was decided $(\alpha=0.05 ; \beta=0.20)$. Four villages in a subdivision were selected randomly. Urban area of Hoshiarpur was also divided into four zones viz north, south, east and west. Out of each zone, one colony was selected randomly. The sample comprised of urban (200) and rural (200) residents. The data was collected by house to house on a predesigned and pretested format. A semi structured interview schedule was used to interview the study subjects. Osteoarthritis was considered if a study subject was suffering from knee pain along with one out of these three symptoms morning stiffness lasting 30 minutes or less/crepitus on motion/osteophytes on radiographs. The data collected were analyzed by using Microsoft office excel 2007 and SPSS 16.0. Continuous variables, such as age, disease duration, etc. were expressed as mean \pm SD. Ordinal variables, such as social status, were expressed as percentages in each category. Informed written consent was taken from study subjects prior to recruitment. All possible information regarding the study was given to the study subjects.

\section{RESULTS}

The mean age of the study subjects was $46.58 \pm 13.49$ and the range was 18 to 88 years. Majority of the respondents belonged to Sikh (50.5\%) and Hindu (45.5\%) religion. Most of the participants were housewives $(80.8 \%)$. Majority of the respondents belonged to nuclear type of families (74.75\%). Majority of them (59.8\%) were from upper middle socioeconomic class (Table 1).

Seventy eight (rural-35, urban-43) of the 400 sampled study subjects fulfilled the classification criteria for knee OA. The estimated average prevalence of symptomatic knee OA was found $19.5 \%$ in district Hoshiarpur. The prevalence was 17.5 and $21.5 \%$ in rural and urban Hoshiarpur respectively. Prevalence was found to be higher among retirees (86.66), though it was not statistically significant. Most of the respondents were literate
(85.5\%). Majority of the respondents were educated up to high (23.5\%), secondary (21\%) or tertiary (20.75\%) level of education. The prevalence was found high in less educated study subjects (27.47\%). The prevalence was significantly associated with age, educational level and menopause $(\mathrm{p}<0.05)$.

\section{DISCUSSION}

The overall prevalence of knee osteoarthritis of 19.5\% in the present study was within the range of 17 to $60.6 \%$ reported across the country and in other countries. However, this prevalence was lower than some previous studies conducted in India (56.6\%). ${ }^{20}$ Other studies showing higher prevalence for osteoarthritis are from Amritsar, ${ }^{21}$ Aligarh $^{22}$ with prevalence of 60.6 and $30.2 \%$ respectively. However, prevalence observed in our study was higher than that found in Shanghai, China ${ }^{23}$ for symptomatic knee osteoarthritis (7.2\%). In these studies, the age groups taken in the sample were above 40 years of age. However in the present study, sample included subjects of age group of 18 to $55+$ years. This may be the reason for lower prevalence in the present study. Moreover, the prevalence was found statistically significant with age.

Though in the present study urban women had higher prevalence $(21.5 \%)$ of knee osteoarthritis as compared to rural women $(17.5 \%)$, the difference was not significant. Our findings support the previous studies done in UT Chandigarh among elderly in year 1999, which revealed a significant difference between prevalence of KOA in rural (32.6\%) and urban (60.3\%) areas. The low prevalence among rural area could be due to more physical work, higher tolerance, less obesity, diet and life style. ${ }^{20}$ On the contrary, Andrianakos (2006) reported that symptomatic knee OA was significantly more common in the rural compared to urban and suburban populations in Athens, Greece. $^{16}$

In our study it was observed that the percentage of people with osteoarthritis increased as the age increased. Maximum prevalence was found in the age group of above 55 years (39.44\%). Age was found to be significantly associated with knee osteoarthritis. This finding is similar to those of the studies conducted in South Delhi, ${ }^{24}$ Dharwad $^{25}$ and at other places. ${ }^{20,26-28}$ The Framingham study represented one of the earliest studies to associate increasing age with worsening knee arthritis.

In the present study, educational status was found to be significantly associated with prevalence of KOA. Less educated study subjects were found to have more prevalence than literates. The reason may be that literate individuals have more awareness about symptoms of disease and they may be more concerned about their health. These findings were similar with previous studies which also quoted that low educational attainment 
Table 1: Prevalence of knee osteoarthritis by sociodemographic variables

\begin{tabular}{|c|c|c|c|c|}
\hline Sociodemographic variable & No. of respondents surveyed & Individuals with $K O A$ & Prevalence (\%) & $p$-value \\
\hline Area & & & & 0.313 \\
\hline Rural & 200 & 35 & 17.5 & \\
\hline Urban & 200 & 43 & 21.5 & \\
\hline Religion & & & & 0.075 \\
\hline Christian & 14 & 2 & 14.28 & \\
\hline Sikh & 204 & 24 & 11.76 & \\
\hline Hindu & 182 & 52 & 28.57 & \\
\hline${ }^{*}$ Age group & & & & 0 \\
\hline $18-24$ & 12 & 0 & 0 & \\
\hline $25-34$ & 73 & 1 & 1.36 & \\
\hline $35-44$ & 89 & 3 & 3.37 & \\
\hline $45-54$ & 117 & 31 & 26.49 & \\
\hline $55+$ & 109 & 43 & 39.44 & \\
\hline \multicolumn{5}{|l|}{${ }^{*}$ Occupation } \\
\hline House wives & 323 & 61 & 18.88 & 0 \\
\hline Retirees & 15 & 13 & 86.66 & \\
\hline Employees & 62 & 4 & 6.45 & \\
\hline *Level of education & & & & 0.036 \\
\hline Illiterate/primary & 91 & 25 & 27.47 & \\
\hline Middle/matriculation & 105 & 19 & 18.09 & \\
\hline Secondary & 84 & 17 & 20.23 & \\
\hline Graduation/post grad & 120 & 17 & 14.16 & \\
\hline Socioeconomic level & & & & 0.080 \\
\hline Lower middle & 83 & 12 & 14.45 & \\
\hline Upper middle & 239 & 45 & 18.82 & \\
\hline High/upper high & 78 & 21 & 26.92 & \\
\hline${ }^{*}$ Menopause & & & & 0 \\
\hline Yes & 212 & 63 & 29.71 & \\
\hline No & 188 & 15 & 7.97 & \\
\hline
\end{tabular}

*Significantly associated with KOA, Chi-square test applied; KoA: Knee osteoarthritis

$(<12$ years) was associated with higher prevalence of knee osteoarthritis. Women with low educational attainment had $50 \%$ higher odds of having radiographic knee osteoarthritis and $65 \%$ higher odds of symptomatic knee osteoarthritis as compared to those with higher education. ${ }^{29}$ Association of higher prevalence of arthritis with less education was also shown by Dunlop et $\mathrm{al}^{30}$ in their study on non-Hispanic Whites, non-Hispanic Blacks and Hispanics. A similar study in North Carolina was done on non-Hispanic Whites and African Americans revealed that White participants with less than a high school (HS) degree living with high poverty had 1.55 times the odds of reporting arthritis compared with White participants with more than a HS degree and low poverty rates. African American participants with less than a HS degree and high poverty rates had 2.06 times the odds of reporting arthritis compared with African American participants with more than a HS degree. ${ }^{31}$

In this study, prevalence of knee osteoarthritis was found to be high among menopausal women $(29.71 \%)$. It is evident that prevalence of OA increases during menopausal age. Salve et al (2010) reported high prevalence of knee osteoarthritis as $47.3 \%$ among perimenopausal women in South West Delhi. ${ }^{24}$ Many studies have shown that loss of estrogen at the time of menopause increases the women's risk of getting osteoarthritis. There are multiple physiopathological mechanisms involved in osteoarthritis. Among them those related to sex hormones particularly estrogens fulfill a relevant role in maintaining the homeostasis of articular tissues and of the joint. ${ }^{32}$ There is a dramatic rise in osteoarthritis prevalence among postmenopausal women. ${ }^{33,34}$ Some studies have also shown significant protective effect of estrogen replacement therapy (ERT) for knee osteoarthritis. ${ }^{35-37}$

No association was found between prevalence and socioeconomic status, in the present study. This study contradicts the findings of Dunlop et $\mathrm{al}^{30}$ and Dalstra et a ${ }^{38}$ which have shown that prevalence of KOA increased with poverty.

In our study, prevalence was found to be high among retirees $(86.6 \%)$. This high prevalence may be because of their older age. Therefore, age may have been a confounding factor. Cooper et al ${ }^{39}$ suggested that knee OA was significantly elevated in subjects whose main job entailed 
more than 30 minutes per day squatting or kneeling, or climbing more than ten flights of stairs per day. The increase in risk associated with kneeling or squatting appeared to be more marked in subjects whose jobs entailed heavy lifting.

\section{CONCLUSION}

The prevalence of KOA found to be $19.5 \%$ in district Hoshiarpur, Punjab. KOA prevalence in urban area was higher $(21.5 \%)$ than rural area $(17.5 \%)$. Association between KOA prevalence and age was found to be significant which revealed that KOA prevalence increased with increase in age. Prevalence was higher in woman with menopause. Educational status was also found to be significantly associated with prevalence of the disease. Women with higher education have less prevalence of KOA than illiterate/less educated counterparts.

\section{REFERENCES}

1. Altman R, Asch E, Bloch D, Bole G, Borenstein D, Brandt K, Hochberg M. Development of criteria for the classification and reporting of osteoarthritis: classification of osteoarthritis of the knee. Diagnostic and Therapeutic Criteria Committee of the American Rheumatism Association. Arthritis Rheum 1986;29(8):1039-1049.

2. Brooks PM. Impact of osteoarthritis on individuals and society: how much disability? Social consequences and health economic implications. Curr Opin Rheumatol 2002;14(5): 573-577.

3. World health organization. World health report. Reducing risks, promoting healthy life. Geneva: WHO 2002. Available at: www.who.int/whr

4. Woolf AD, Pfleger B. Burden of major musculoskeletal conditions. Bulletin of the World Health Organization 2003; 81(9):646-656.

5. Velentina BP. Education for arthritis patients. A community pharmacy based pilot project. Pharmacy Practice 2009;7(2): 88-93.

6. Mody G, Woolf A. A report on global burden musculoskeletal disorders. Business briefing of pharmacotherapy association 2003. Available at: http://www.touchbriefings.com/pdf/26/ ept031p mody and woolf Ir.pdf

7. Arfaj AA, Boukai AA. Prevalence of radiographic knee osteoarthritis in Saudi Arabia. Clin Rheumatol 2002;21(2):142-145.

8. Shammari AS, Khoja T, Alballa S, Kremlin M, Charles ST. Obesity and clinical osteoarthritis of the knee in primary healthcare. Med Sci Res 1995;23:255-256.

9. Maurer K. Basic data on osteoarthritis knee, hip, and sacroiliac joints. US department of health education and welfare. Report Number 1979;213.

10. Meulenbelt I, Bijkerk C, DeWildt SC. Investigation of the association of the CRTM and CRTL1 genes with radiographically evident osteoarthritis in subjects from the Rotterdam study. Arthritis Rheum 1997;40(10):1760-1765.

11. Guccione AA, Felson DT, Anderson JJ. Specific diseases and their effects on functional limitations in elders in the Framingham Study. Am J Public Health 1994;84(3):351-358.
12. McCormick A, Fleming D, Charlton J. Morbidity statistics from general practice: fourth national study, 1991-1992. Series MB5 No 3. London: HMSO; 1995.

13. CDC and arthritis foundation. A national public health agenda for osteoarthritis 2010. http://www.cdc.gov/arthritis/ docs/oaagenda.pdf (accessed 20 Jan 2013).

14. Creamer P, Hochberg MC. Osteoarthritis. Lancet 1997; 350(9076):503-508.

15. Oliveria SA, Felson DT, Reed JI Cirillo PA, Walker AM. Incidence of symptomatic hand, hip and knee osteoarthritis among patients in a health maintenance organization. Arthritis Rheum 1995;38(8):1134-1141.

16. Andrianakos AA, Kontelis LK, Karamitsos DG, Aslanidis SI, Georgountzos AI, Kaziolas GO, Dantis PC. Prevalence of symptomatic knee, hand, and hip osteoarthritis in Greece: The ESORDIG study. J Rheumatol 2006;33(12):2507-2513.

17. Page CJ, Hinman RS, Bennell KL. Physiotherapy management of knee osteoarthritis. Int J Rheumatic Diseases 2011;14(2): 145-151.

18. American college of rheumatology subcommittee on osteoarthritis guidelines. Recommendations for the medical management of osteoarthritis of the hip and knee. 2000 update. Arthritis Rheum 2000;43(9):1905-1915.

19. Yelin E. The economics of osteoarthritis. In: Brandt KD, Doherty M, Lohmander LS (eds.) Osteoarthritis. Oxford, Oxford University Press 2003;17-21.

20. Sharma MK, Swami HM, Bhatia V, Verma A, Bhatia SP, Kaur G. An epidemiological study of correlates of osteoarthritis in geriatric population of UT Chandigarh. Indian J Comm Med 2007;32(1):77-78.

21. Padda AS, Mohan V, Singh J. Health profile of aged persons in urban and rural field practice area of medical college Amritsar. Indian J Com Med 1998;23(2):72-76.

22. Khan JA, Khan Z, et al. A study of the leading causes of illness and physical disability in an urban aged population. Indian J Prev Soc Med 2001;32(3\&4):121-127.

23. Du H, Chen SL, Bao CD, Wang XD, Lu Y, Gu YY, Nishioka K. Prevalence and risk factors of knee osteoarthritis in Huang-Pu District, Shanghai, China. Rheumatol Int 2005;25(8):585-590.

24. Salve H, Gupta V, Palanivel C, Yadav K, Singh B. Prevalence of knee osteoarthritis amongst perimenopausal women in an urban resettlement colony in South Delhi. Indian J Public Health 2010;54(3):155-157.

25. Patil PS, Dixit UR, Shettar CM. Risk factors of osteoarthritis knee: a cross-sectional study. J Dent Med Sci 2012;2(5): 8-10.

26. Joshi K, Kumar R, Avasthi A. Morbidity profile and its relationship with disability and psychological distress among elderly people in Northern India. Int J Epiodemiol 2003; 32(6):978-987.

27. Kopec JA, Rahman MM, Berthelot JM, Le PetitC, Aghajanian J, Sayre EC, Cibere J, Badley EM. Descriptive epidemiology of osteoarthritis in British Columbia, Canada. J Rheumatol 2007;34(2):386-393.

28. Akinpelu AO, Alonge TO, Adekanla BA, Odole AC. Prevalence and pattern of symptomatic knee osteoarthritis in Nigeria: a community-based study. Int J Allied Health Sci Prac 2009;7(3):1-7.

29. Callahan LF, Shreffler J, Siaton BC, Helmick CG, Schoster B, Schwartz TA, Jordan JM. Limited educational attainment and radiographic and symptomatic knee osteoarthritis: a cross-sectional analysis using data from the johnston county (North Carolina) osteoarthritis project. Arthritis Res Ther 2010;12(2):R46. 
30. Dunlop DD, Manheim LM, Song J, Chang RW. Arthritis prevalence and activity limitations in older adults. Arthritis Rheum 2001;44(1):212-221.

31. Callahan LF, Shreffler J, Mielenz T, Schoster B, Kaufman JS, Xiao C, Sloane PD. Arthritis in the family practice setting: associations with education and community poverty. Arthritis Rheum 2008;15(7):1002-1008.

32. Gokhale JA, Frenkel SR, Dicesare PE. Estrogen and osteoarthritis. Am J Orthop 2004;33(2):71-80.

33. Srikanth VK, Fryer JL, Zhai G, Winzenberg TM, Hosmer D, Jones $\mathrm{G}$. A meta-analysis of sex differences prevalence, incidence and severity of osteoarthritis. Osteoarthritis Cartilage 2005;13(9):769-781.

34. Lawrence RC, Felson DT, Helmick CG, Arnold LM, Choi H, Deyo RA, Gabriel S. National arthritis data workgroup. Estimates of the prevalence of arthritis and other rheumatic conditions in the United States. Part II. Arthritis Rheum 2008;58(1):26-35.
35. Wluka AE, Davis SR, Bailey M, Stuckey SL, Cicuttini FM. Users of oestrogen replacement therapy have more knee cartilage than non-users. Ann Rheum Dis 2001;60(4):332-336.

36. Spector TD, Nandra D, Hart DJ, Doyle DV. Is hormone replacement therapy protective for hand and knee osteoarthritis in women? The Chingford Study. Ann Rheum Dis 1997;56(7):432-434

37. Hart DJ, Doyle DV, Spector TD. Incidence and risk factors for radiographic knee osteoarthritis in middle-aged women. The Chingford Study. Arthritis Rheum 1999;42(1):17-24.

38. Dalstra JA, Kunst AE, Borrell C, Breeze E, Cambois E, Costa G, Mackenbach JP. Socioeconomic differences in the prevalence of common chronic diseases. An overview of eight European countries. Int J Epidemiol 2004;34(2):316-326.

39. Cooper C, McAlindon T, Coggon D, Egger P, Dieppe P. Occupational activity and osteoarthritis of the knee. Ann Rheum Dis 1994;53(2):90-93. 